\title{
Application of Neural Networks in Preform Design of Aluminium Upsetting Process Considering Different Interfacial Frictional Conditions
}

\author{
Ajay Kumar Kaviti ${ }^{1, *}$, K.K. Pathak ${ }^{2}$, and M.S. Hora ${ }^{3}$ \\ ${ }^{1}$ Department of Mechanical Engineering, SISTec, Bhopal (MP) India \\ ajaykaviti@yahoo.com \\ ${ }^{2}$ Advanced Materials and Processes Research Institute (CSIR), Bhopal (MP) India \\ ${ }^{3}$ Department of Applied Mechanics, MANIT, Bhopal (MP) India
}

\begin{abstract}
Design of the optimum preform for near net shape manufacturing is a crucial step in upsetting process design. In this study, the same is arrived at using artificial neural networks (ANN) considering different interfacial friction conditions between top and bottom die and billet interface. Back propagation neural networks is trained based on finite element analysis results considering ten different interfacial friction conditions and varying geometrical and processing parameters, to predict the optimum preform for commercial Aluminium. Neural network predictions are verified for three new problems of commercial aluminum and observed that these are in close match with their simulation counterparts.
\end{abstract}

Keywords: Artificial neural network; Preform; finite element; upsetting; deformation.

\section{Introduction}

Upsetting is an important metal forming operation. It is a class of bulk forming operation where large deformation is given to the material for shape and property modification. The major issue, which restricts imparting large deformation to the billet is the bulging induced tensile stress which later result in cracking. Bulge is also undesirable from near net shape manufacturing point of view as it will require secondary processing like trimming. To obtain the near net shape, preform design of the billets is a powerful solution. Considerable amount of literature are available on the preform design in forging process.

Roy et al. (1994) report application of neural networks in interpolation of preform shapes in plane strain forgings. Ranatunga et al. (1996) present preform designing techniques based on the upper bound elemental technique (UBET) with evidence of effective material usage and extended overall die-life. Lee et al. (1997) report application of an upper-bound elemental technique in preform design for asymmetric forging which is validated through experiments. Liu et al. (1998) present a preform design

* Corresponding Author.

S. Chaudhury et al. (Eds.): PReMI 2009, LNCS 5909, pp. 98-105, 2009.

(C) Springer-Verlag Berlin Heidelberg 2009 
method which combines the FEM \& upper bound based reverse simulation technique. The billet designed using this technique achieves a final forging with minimum flash. Ko et al. (1999) describe a new method of preform design in muti-stage metal forming processes considering workability limited by ductile fracture. Neural networks and Taguchi method are used for minimizing the objective function. Srikanth et al. (2000) present a continuum sensitivity analysis approach for the computation of the shape sensitivity, which is later used for the purpose of preform design and shape optimization in forging process. Chang et al. (2000) propose reverse simulation approach clubbed with finite element analyses for preform design. Bramley et al. (2001) report a new method named as tetrahedral upper bound analysis which enables a more realistic flow simulation to be achieved. Antonio et al. (2002) presents an inverse engineering formulation together with evolutionary search schemes for forging preform design. Shim et al. (2003) presents optimal preform design for 3D free forgings using sensitivity approach and FEM. Tomov et al. (2004) reports preform design of axisymmetric forging using FE software FORM-2D. Ou et al. (2004) reports finite element (FE) based forging simulation and optimization approach in order to achieve net-shape forging production for aero engine components. Effects of die-elastic deformation, thermal distortion and press-elasticity were considered. Poursina et al. (2004) proposes a FEM and GA based preform design procedure for axisymmetric forgings in view to achieve high quality products. Thiyagarajan et al. (2005) presents a 3-D preform shape optimization method for the forging process using the reduced basis technique. Repalle et al. (2005) presents reliability-based optimization method for preform shape design in the forging. Antonio et al. (2005), reports an inverse approach for preform design of forged components under minimal energy consumption using FEM and genetic algorithms. Park and Hwang et al. (2007) reports preform design for precision forging of rib type aerospace components using finite element analysis. Poshala et al. (2008) carried out formability analysis and its experimental validations for aluminum preforms using neural network. Haluk Tumer et al. (2008) optimised die and preform to minimize hardness distribution in back extrusion process using Nelder-Mead search algorithm integrated with the finite element model. Although substantial literature on preform design is available, they address it as individual problem considering one or few parameters.

The main objective of this study is to devise a generalized procedure of preform design considering various parameters. For this, neural network has been used for preform design of the upsetting process. In this study effect of critical factors including different preform shapes, interfacial friction conditions, and their effect on the final deformed profiles are studied using FE simulation. Ten cases of different interfacial friction conditions are considered for the same. Based on the simulation results, a back propagation neural network is trained to provide guidelines for selection of parameters to result in near net shape manufacturing. Neural network predictions are verified with three numerical examples for commercial Aluminium.

\section{Artificial Neural Networks}

Artificial neural network attempts to imitate the learning activities of the brain. In an artificial neural network (ANN), the artificial neuron or the processing unit may have 
several input paths corresponding to the dendrites in the biological neuron. The units combine usually, by a simple summation, the weighted values of these paths. The weighted value is passed to the neuron, where it is modified by threshold function. The modified value is directly presented to the next neuron. In Fig. 1 a 3-4-2 feed forward back propagation artificial neural network is shown. The connections between various neurons are strengthened or weakened according to the experiences obtained during the training. The algorithm for training the back propagation neural network can be explained in the following steps-

Step1 - Select the number of hidden layers, number of iterations, tolerance of the mean square error and initialize the weights and bias functions.

Step2 - Present the normalized input -output pattern sets to the network. At each node of the network except the nodes on input layer, calculate the weighted sum of the inputs, add bias and apply sigmoid function

Step3-Calculate total mean error. If error is less than permissible limit, the training process is stopped. Otherwise,

Step4 -Change the weights and bias values based on generalized delta rule and repeat step 2 .

The mathematical formulations of training the network can be found in Ref. 21.

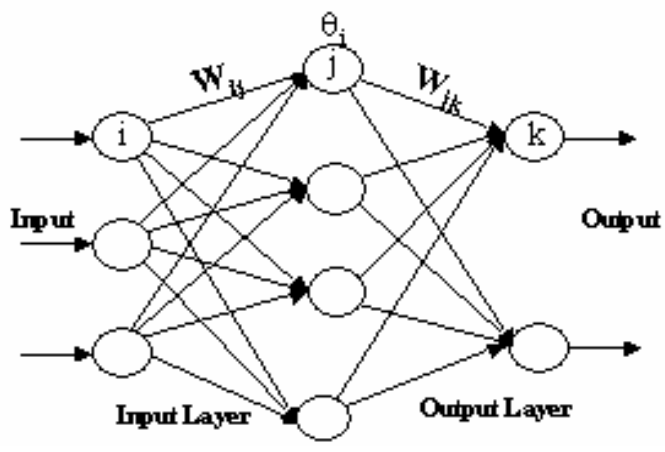

Fig. 1. Neural network

\section{Methodology}

In Fig.2, schematic undeformed and deformed billets are shown. Let top, middle and bottom diameters of these billets be $a, b c$, and $a_{1}, b_{1}, c_{1}$ respectively. Their diameter ratios with respect to top diameter, can be expressed as $R_{1}=b / a, R_{2}=c / a$ and $r_{1}=b_{1} / a_{1}$, $r_{2}=c_{1} / a_{1}$. It is obvious that for near net shape manufacturing, $r_{1}$ and $r_{2}$ should be one. Since deformed profiles depend on geometrical and frictional conditions, large numbers of variation of these parameters are accounted. Ten sets of interfacial frictional parameters and 38 sets of geometrical conditions making total 380 combinations are considered in this study for commercial Aluminium. Finite element simulations of these cases are carried out to obtain the deformation behavior. Based on these results, 

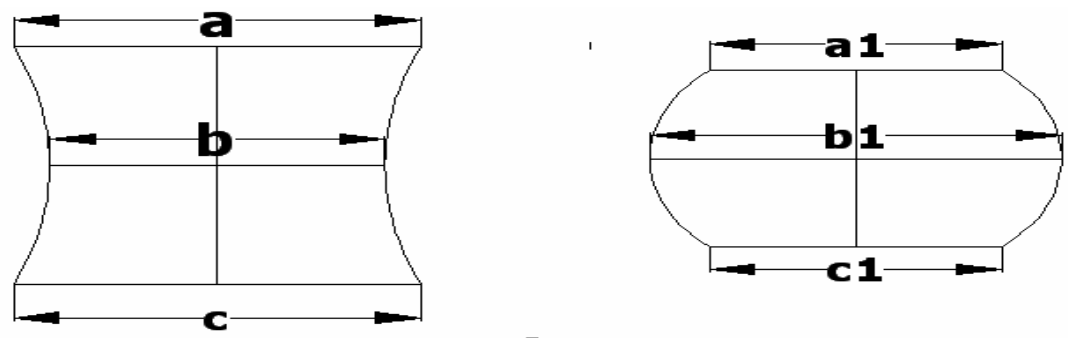

Fig. 2. Initial and final shapes of billet

back propagation neural networks are trained to predict desired preform for given $f_{t}$, and $f_{b}$ values to result in near net shape upsetting.

\section{Geometrical, Material and Processing Parameters}

Cylindrical specimens of $40 \mathrm{~mm}$ top diameter and $40 \mathrm{~mm}$ height are used for simulation studies of commercial Aluminium. The central and bottom diameters are considered as 28, 30, 32, 34 36, 38 and $39 \mathrm{~mm}$. In this way center and top diameter ratio and bottom and top diameter ratio $\left(\mathrm{R}_{1}\right.$ and $\left.\mathrm{R}_{2}\right)$, also named as preform ratios, comes out to be $0.7,0.75,0.8,0.85,0.9,0.95$ and 0.975 respectively. Ten combinations of interfacial frictions, Coulomb friction, at top and bottom surfaces of billet and platens considered for simulation studies are given in Table 1.

Table 1. Frictional conditions at die and billet interface

\begin{tabular}{|c|c|c|}
\hline S.No & $\begin{array}{l}\mathbf{f}_{\mathbf{t}} \text { (Friction between top } \\
\text { die and billet interface) }\end{array}$ & $\begin{array}{l}\mathbf{f}_{\mathbf{b}} \text { (Friction between bottom die } \\
\text { and billet interface) }\end{array}$ \\
\hline 1 & 0.1 & 0.1 \\
\hline 2 & 0.2 & 0.1 \\
\hline 3 & 0.2 & 0.2 \\
\hline 4 & 0.3 & 0.1 \\
\hline 5 & 0.3 & 0.2 \\
\hline 6 & 0.3 & 0.3 \\
\hline 7 & 0.4 & 0.1 \\
\hline 8 & 0.4 & 0.2 \\
\hline 9 & 0.4 & 0.3 \\
\hline 10 & 0.4 & 0.4 \\
\hline
\end{tabular}



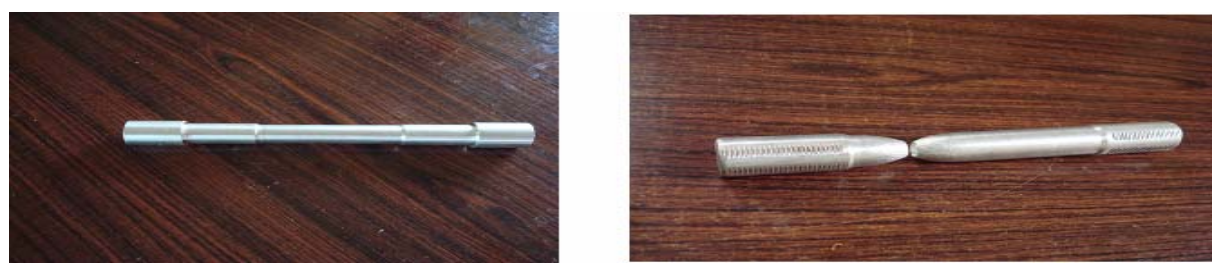

Fig. 3. Tensile specimens (Before $\&$ after test)

Table 2. Material Properties

\begin{tabular}{|c|c|}
\hline Properties & Commercial Aluminium \\
\hline Youngs modulus (E)MPa & $7 \times 10^{4}$ \\
\hline Poisson's ratio (v) & 0.33 \\
\hline Strengthcoefficient (K)MPa & 225.4 \\
\hline Hardening exponent (n) & 0.095 \\
\hline
\end{tabular}

The 38 cases of geometric parameters accounted in the study. Material properties of commercial Aluminium have been obtained by conducting tensile tests. Specimens of gauge length $80 \mathrm{~mm}$, prepared as per ASTM standard, are tested in a Shimadzu make Universal Testing Machine (UTM). The test and tested specimens of commercial aluminum are shown in Fig.3. The engineering stress \& strain are converted into their true counterparts using standard relationships (Kalpakjian and Schmid ,2004). Based on these results, material modeling is carried out. The post yielding behaviour is modeled using the power law equation (Meyers and Chawla, 1997):

$$
\sigma=\mathrm{k} \varepsilon^{\mathrm{n}}
$$

Where $\mathrm{k}$ is the strength coefficient and $\mathrm{n}$ is the hardening exponent. The material properties evaluated and adapted for FE simulation are given in Table 2.

\section{FE Simulation}

Finite element analyses of the upsetting process are carried out using MSC.Marc software (Ref 22). Curved profiles of specimens are modeled as arcs between top,

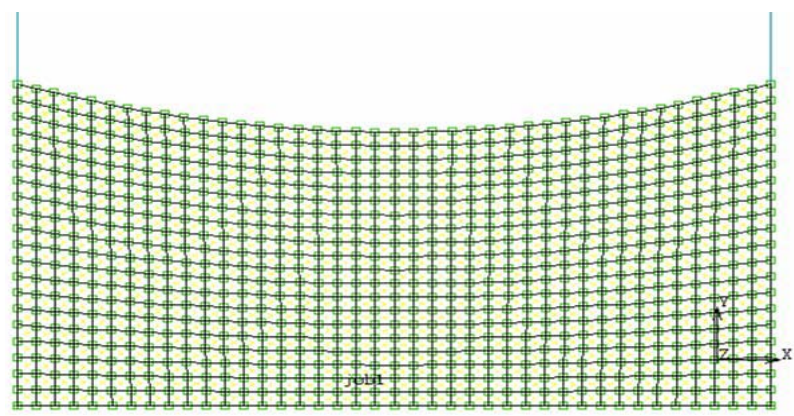

(a)

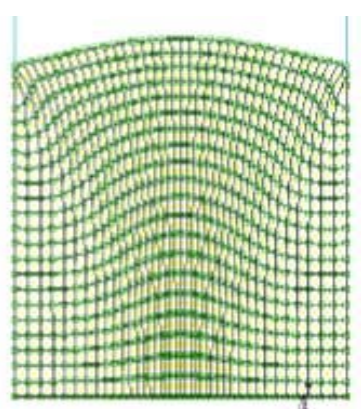

(b)

Fig. 4. FEM models (a) before deformation (b) after deformation 
middle and bottom diameters using ARC command of the software. Taking advantage of the symmetrical conditions, axisymmetrical formulation is adopted. Four nodded quadrilateral elements are used for the FE modeling. There are 800 elements and 861 nodes in the model. Considering the variation in 38 geometrical cases and ten cases of frictional conditions, total 380 cases are simulated for commercial Aluminium. Punch and die are modeled as rigid bodies. Bottom die is fixed whereas punch is movable which is given the displacement boundary condition. All the commercial Aluminium billets are identically deformed to final height of $28 \mathrm{~mm}$ viz. $30 \%$ reduction in height. A typical FE and deformed models are shown in Fig.4. Geometrical parameters of deformed and undeformed conditions for all the 380 cases are recorded separately for commercial aluminum.
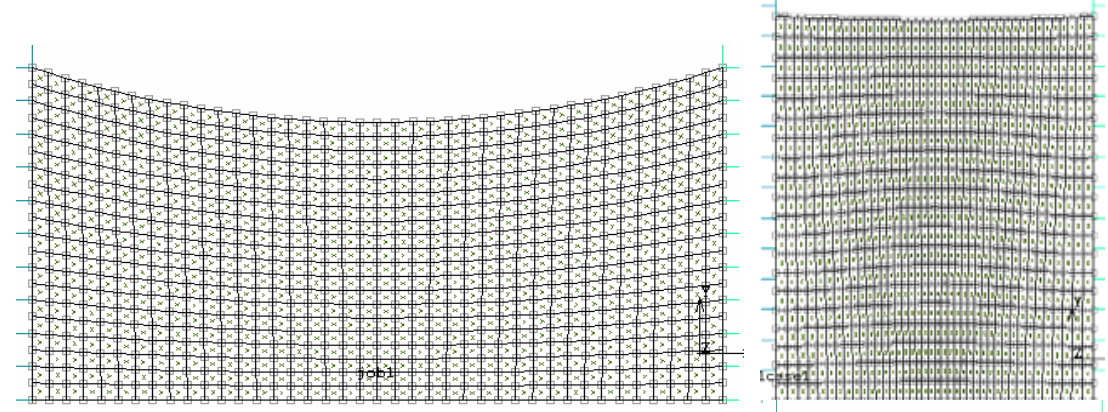

(a)
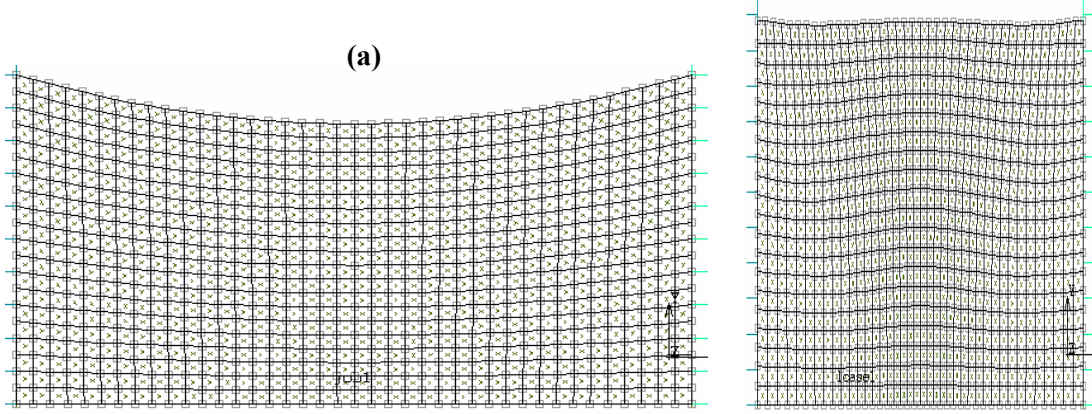

(b)
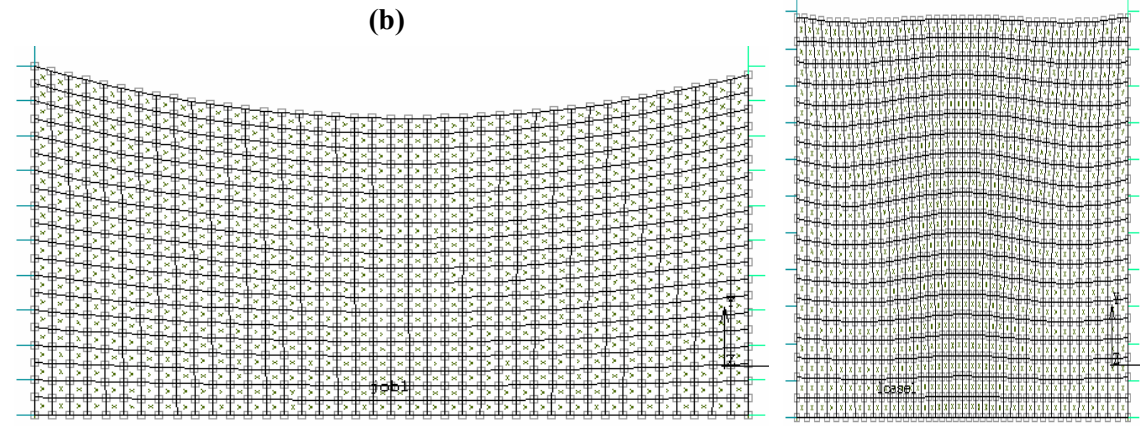

(c)

Fig. 5. Initial and deformed shapes of Aluminium (a) $f_{t}=0.28, f_{b}=0.28, R_{1}=0.835, R_{2}=1$ (b) $f_{t}=$ $0.2, \mathrm{f}_{\mathrm{b}}=0.2, \mathrm{R}_{1}=0.86, \mathrm{R}_{2}=1$ (c) $\mathrm{f}_{\mathrm{t}}=0.35, \mathrm{f}_{\mathrm{b}}=0.25 \mathrm{R}_{1}=0.83, \mathrm{R}_{2}=0.975$ 


\section{Numerical Validation}

FE results in terms of diameter ratios are used for training neural networks. One 4-6-2 back propagation neural network for commercial Aluminium has been used for the training. $f_{t}, f_{b}, r_{1}, r_{2}$ are input and $R_{1}$, and $R_{2}$ are output parameters. The error limit is 0.002 and it took 1447695 epochs to converge the desired limit. The trained network is tested for three new problems of commercial aluminum upsetting to show the efficacy of the neural network predictions. The input parameters for them are given in Table3. The predicted preforms $\left(\mathrm{R}_{1}\right.$ and $\mathrm{R}_{2}$ values) are used for validation through $\mathrm{FE}$ simulation. The ' $r_{1}$ and $r_{2}$ ' values predicted are very close to the near net shape manufacturing. Maximum error is $1 \%$ which is very less. The initial and final deformed meshes for these cases are shown in Fig5. It can be observed that deformed profiles are close to the near net shapes of perfect cylinders.

Table 3. Numerical Validation of ANN for commercial Aluminium

\begin{tabular}{|l|l|l|l|l|l|l|l|l|l|l|}
\hline S.No & $\mathrm{f}_{\mathrm{t}}$ & $\mathrm{f}_{\mathrm{b}}$ & $\mathrm{R}_{1}$ & $\mathrm{R}_{2}$ & $\mathrm{r}_{1 \text { (Actual) }}$ & $\mathrm{r}_{1(\mathrm{FEM})}$ & \%Error & $\mathrm{r}_{2 \text { (Actual) }}$ & $\mathrm{r}_{2(\mathrm{FEM})}$ & $\%$ Error \\
\hline 1 & 0.28 & 0.28 & 0.835 & 1 & 1 & 0.99 & 1 & 1 & 0.999 & 0.1 \\
\hline 2 & 0.20 & 0.20 & 0.86 & 1 & 1 & 0.998 & 0.2 & 1 & 0.999 & 0.1 \\
\hline 3 & 0.35 & 0.25 & 0.825 & 0.975 & 1 & 0.995 & 0.5 & 1 & 1.003 & 0.3 \\
\hline
\end{tabular}

\section{Conclusion}

In this study artificial neural networks have been used for the design of preforms for the cylindrical billet upsetting. Based on the results of $380 \mathrm{FE}$ simulations a back propagation neural network is trained for commercial Aluminium. Trained networks are first verified with three numerical examples. It is found that simulation and network predictions are in close match. This study also demonstrates that ANN can be effectively used for preform design. It is hoped, this study will help design engineers in fast and reliable predictions of optimum preforms under different frictional conditions for net shape manufacturing.

\section{References}

1. Antonio, C.A.C., Dourado, N.M.: Metal-forming process optimisation by inverse evolutionary search. Journal of Materials Processing Technology 121(2-3), 403-413 (2002)

2. Antonio, C.C., Castro, C.F., Sousa, L.C.: Eliminating forging defects using genetic algorithms. Materials and Manufacturing Processes 20(3), 509-522 (2005)

3. Bramley, A.: UBET and TEUBA: fast methods for forging simulation and preform design. Journal of Materials Processing Technology 116(1), 62-66 (2001)

4. Chang, C.C., Bramley, A.N.: Forging preform design using a reverse simulation approach with the upper bound finite element procedure. Proceedings of The Institution of Mechanical Engineers Part C: Journal of Mechanical Engineering Science 214(1), 127-136 (2000)

5. Tumer, H., Sonmez, F.O.: Optimum shape design of die and preform for improved hardness distribution in cold forged parts. Journal of Materials Processing Technology (Article in the Press) 
6. Ko, D.C., Kim, D.H., Kim, B.M.: Application of artificial neural network and Taguchi method to preform design in metal forming considering workability. International Journal of Machine Tools \& Manufacture 39(5), 771-785 (1999)

7. Lee, J.H., Kim, Y.H., Bae, W.B.: An upper-bound elemental technique approach to the process design of asymmetric forgings. Journal of Materials Processing Technology 72(1), 141-151 (1997)

8. Liu, Q.B., Wu, S.C., Sun, S.: Preform design in axisymmetric forging by a new FEMUBET method. Journal of Materials Processing Technology 74(1-3), 218-222 (1998)

9. Meyers, M.A., Chawla, K.K.: Mechanical Behaviour of Materials. Prentice-Hall, Englewood Cliffs (1999)

10. Ou, H., Lan, J., Armstrong, C.G.: An FE simulation and optimisation approach for the forging of aeroengine components. Journal of Materials Processing Technology 151(1-3), 208-216 (2004)

11. Park, J.J., Hwang, H.S.: Preform design for precision forging of an asymmetric rib-web type component. Journal of Materials Processing Technology 187, 595-599 (2007)

12. Poshala, G., Ganesan, P.: An analysis of formability of aluminium preforms using neural network. Journal of Materials Processing Technology 205(1-3), 272-282 (2008)

13. Poursina, M., Antonio, C.A.C., Castro, C.F.: Preform optimal design in metal forging using genetic algorithms. Engineering Computations 21(5-6), 631-650 (2004)

14. Ranatunga, V., Gunasekera, J.S.: UBET-based numerical modeling of bulk deformation processes. Journal of Materials Engineering and Performance 15(1), 47-52 (2006)

15. Repalle, J., Grandhi, R.V.: Reliability-based preform shape design in forging. Communications in Numerical Methods In Engineering 21(11), 607-617 (2005)

16. Roy, R., Chodnikiewicz, K., Balendra, R.: Interpolation of Forging preform shapes using neural networks. Journal of Materials Processing Technology 45(1-4), 695-702 (1994)

17. Thiyagarajan, N., Grandhi, R.V.: Multi-level design process for 3-D preform shape optimization in metal forming. Journal of Materials Processing Technology 170(1-2), 421-429 (2005)

18. Tomov, B.I., Gagov, V.I., Radev, R.H.: Numerical simulations of hot die forging processes using finite element method. Journal of Materials Processing Technology 153, 352-358 (2004)

19. Shim, H.: Optimal preform design for the free forging of 3D shapes by the sensitivity method. Journal of Materials Processing Technology 134(1), 99-107 (2003)

20. Srikanth, A., Zabaras, N.: Shape optimization and preform design in metal forming processes. Computer Methods in Applied Mechanics and Engineering 190(13-14), 1859-1901 (2000)

21. Hertz, J., Krogh, A.: Introduction to the Theory of Neural Networks: Addison- Wesley Publishing Company. Addison-Wesley Publishing Company, Reading (1991)

22. User's manual, MSC. Marc, MSC Software Corporation, Santa Ana, California 92707 USA (2005) 